\title{
Living donor liver transplant between physicians: two viewpoints
}

Cite as: CMAJ 2020 June 29;192:E729-31. doi: 10.1503/cmaj.200231

\section{A recipient's view}

I saw the snake, but not in time. Its bite was not life threatening, and I received antibiotics for the cellulitis that ensued. That was March 2018 in Southeast Asia. What followed was months of fever and chills, and two months of rash, skin sloughing and arthralgias. I was diagnosed with Stevens-Johnson syndrome, an undesired effect of the antibiotic. I knew it could affect end organs. By November, I was fatigued, increasingly encephalopathic and unable to work. The syndrome had affected my liver. I was told I needed a transplant and was given instructions to find a donor. I didn't know how to begin. As a kidney transplant surgeon, I become involved later in the process; I had little experience counselling patients on how to find a living donor.

There's no clear algorithm. I knew I couldn't advocate for myself. That could be very awkward for both a potential donor and me. The transplant team suggested that my wife, Margaret, a senior physician, take this role. She worked daily to find a donor, contacting friends and colleagues around the world. My family came forward courageously, but their livers were too small or they were declined for other reasons. Many others also stepped forward, but their livers too were not quite right. I learned this later.

The process is frustratingly opaque. I understand the transplant program's commitment to keeping recipients and donors separate, but from the patient side, it's difficult. Are there zero, two or 100 people under consideration for living donation? On dark days, I wondered if there was anybody out there. I was also on the list for a deceased donor and was

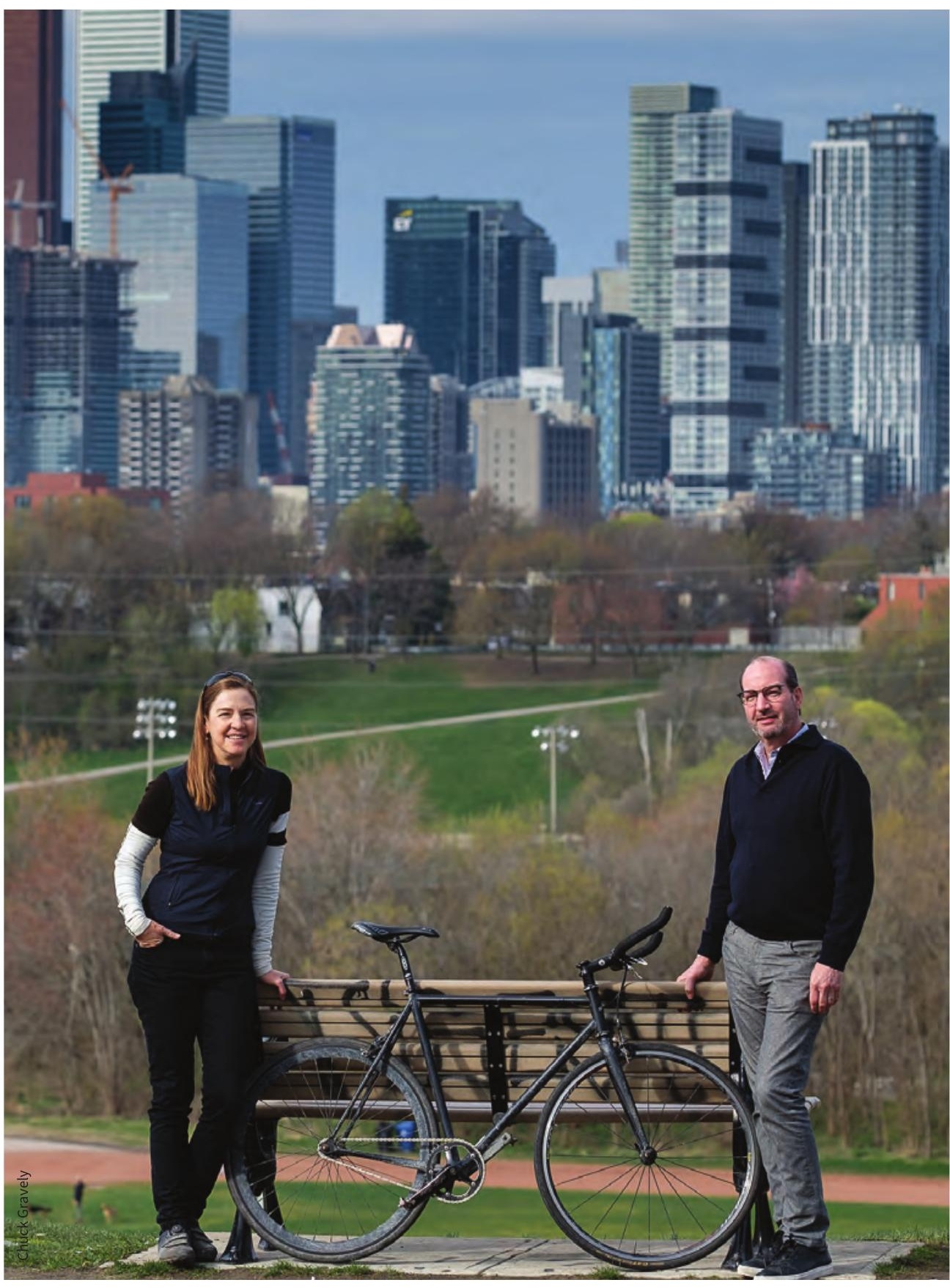

Dr. Marie Faughnan donated half of her liver to her colleague Dr. Robert Stewart in June 2019. 
told I would be prioritized when my twomonth mortality risk reached $50 \%$. This might have entailed a few years of waiting and not working. I languished, completely in the dark. Being told "We will tell you when it happens" is not very reassuring to anyone, much less someone like me, who is used to turning the dials. I felt a loss of control like I had never experienced. I was also frightened. My life expectancy had never before been reduced to blunt, frightening statistics. And I was stunned by the rapidity of it all. Mere weeks had passed since I'd learned that I was ill and spontaneous recovery was not possible.

Not knowing where I stood vis-à-vis a living donor was like running a race, being cheered onward by my doctors, but not knowing where the finish line was. Are we there yet? Maybe it would have been easier if I'd focused on the running, the present, rather than trying so hard to bring the future into focus, to see that finish line. I found that difficult.

I felt helpless. I was unable to console my children or assist my wife. I walked a lot - and I went to appointments. I looked around the waiting room at my pretransplant clinic visits: chronic illness was palpable. At times I tried to believe I was not one of them. A patient of mine connected to the media asked whether I was interested in being interviewed; headline: "Transplant surgeon needs transplant." I paused, and I continued to walk.

Some seven months passed. Then, in May 2019, the telephone rang: a candidate had come forward who might be appropriate. Once everything was cleared, I learned who she was. After an international search, Marie was my donor. Marie, a doctor I work with in my hospital! I have known her for many years. We'd looked after some patients together, and she and my wife are colleagues.

How does one react? It was no longer only me. Now two people were involved; two people with names, lives, families and friends. The courageous risk-taker is the donor. An athletic person around my own age checks into hospital, knowing that she will be made sick, but should recover well. Who does this? Is there an anatomic substrate of such an altruistic person? There is evidence that donors possess a unique phenotype with larger amygdalas than the rest of us - caring, feeling, wanting to make life-altering change for another person. ${ }^{1}$ The cognitive processing of this type of decision-making is actively being researched. I do know that these are special human beings who are not satisfied with standing by and hoping that someone else will make the big decision, the altruistic gift. Maybe they view urgency from a more personal perspective.

When Marie and I spoke the night before surgery, we were both pensive but not scared. I was about to receive a chance, and she was resolute. I told her I hoped her landing would be soft, and that recovery would be hers first. As we were "asleep in the OR," anxious family members met each other for the first time in the post-op area. My life was saved, and when I saw Marie the next morning, she looked great. We walked the hallway together. We were discharged days 4 and 5 after surgery, each feeling well.

After discharge began a gradual transformation. After 21 years working as a transplant surgeon, I began to see my patients through this lens reflected backward on the physician. I know what it is to be a transplant patient. The ramifications of this disease are about much more than a liver. Pre-op, I felt separate from what was happening; I couldn't believe I was really the patient. Now, I believe. I am a patient, one fortunate person in a cohort of transplant survivors. I have a greater appreciation for the psychological burden of disease and what patients invest to execute the things we ask. Imaging studies, filling prescriptions and diagnostic procedures are so time consuming. I learned that being critically ill is a full-time job. Previously, I never really looked at the people in my waiting room. I found my next patient, without considering the collective suffering in front of me. Now I see it clearly in all of their faces - each has their own story. At the end of a patient's visit, with my hand on the door, I now routinely look over my shoulder, into the patient's face, to convince myself that their agenda has been fully addressed. If I'm not certain, I sit down again.

Stress is melting away for me and for my family, who have endured a horrific ordeal. I see now that I didn't fully know I was sick. I had internalized our medical mantra: "Push, push harder, push even harder." Our own medical culture is not helpful to healing oneself. I offer compassion and empathy to my patients. It is genuine. But I regard illness in myself as a weakness. This makes it next to impossible to sit in the passenger seat instead of steering. I now know, deep down, that I am as vulnerable to disease as anybody else and am more able to humbly ask for others' help when I am unable to heal myself. As doctors, we need to give ourselves permission to experience illness, as we do for our patients.

A special person said, "He needs a donor - why not me?" I will always cherish this gift of an organ and I will pay it forward to the best of my ability. I will help the campaign for organ donation in gratitude to Marie and to the outstanding transplant team who save lives like mine routinely. It has been a transformative experience for me as a person. I am a different doctor.

\section{A donor's view}

The decision took some time. The path forward had some scary moments, but none that challenged me as much as the decision.

My friend made a plea to our University of Toronto community for a liver donor for her husband, Rob. Both were doctors I had known for many years. My first reaction was "Someone must do this!" I could see my colleagues felt the same way. But the idea of being a living liver donor sounded outrageous and risky. I casually floated the question to my colleagues: "What is it like to be a liver donor?" My uncertainty was mirrored back to me. I stayed stuck in that uncertainty for a couple of months. Maybe it was just another one of my crazy ideas.

I do my best thinking when I am riding my bike, relaxed and spinning my legs. I have followed the same route to St. Michael's Hospital for 20 years. On my way in to work, solutions to problems come easily. On my way home, the city flows through me, clearing my head. The prospect of being a liver donor was a recurring "way in to work" topic: Someone needs to donate half of their liver to Rob. Why isn't that someone me? Is it risky? 
Too stressful for family? Risking my health, when I had commitments to keep?

I finally took the first real step: I asked someone in the know. I messaged a good cycling friend who is also a liver transplant surgeon and asked what it was like to be a liver donor. Over coffee, he explained the surgery and showed me their outcomes from the first 800 donors. Excellent outcomes. It looked maybe manageable. He told me that there was no pressure on me to do this. I felt no pressure from the outside. On the inside, my mind continued to spin. Why not me? Not too scary (but a little scary). I signed up to get checked. I was mostly decided. I told my husband; he was concerned about the risks. I didn't tell anyone else. What if I wasn't a good candidate? What if I didn't go through with it?

Getting checked out was a test in itself. The biggest issue was whether I had enough liver for both of us to survive while regenerating. I was tested. I waited. Spinning in my own head, not wanting to scare my husband and not talking with anybody else. At one point, I thought, "Maybe the best thing would be if they told me I'm not a good candidate; then I would have tried, without undergoing surgery!" That stuck for two days, and then I realized that it was just fear speak- ing, that I needed to face that fear and that I really wanted to do this. I waited impatiently. I was so excited when I heard. Yes, I am a good candidate!

I told my teenaged children they had veto power. They did not veto it. They said they understood my decision, that it made sense to them, that it was in keeping with my personal life philosophy. Not a crazy idea! I told the program they could tell Rob and his wife, Marg. I told people at work. I was ill prepared for the tsunami of support and gratitude. I was overwhelmed, not having thought through how people would react, but it was lovely; it made the path so much easier.

I wanted to get the surgery done soon. I made my peace with planned conferences and personal plans, and time off my bike. All of it seemed minor and manageable, especially with everyone around me so supportive. It was going to be just five days in hospital, one month off work and six weeks off the bike. Easy, compared with what Rob and Marg were living with. That is how it went, and even a little better. I was out of hospital after four days, back at work and on my bike at four weeks. I had coffee with Rob and was thrilled to see his excellent progress! It helped me thrive and recover more quickly myself. When I returned to work, everyone was smiling - even people I had never really seen smile before. That felt really good.

Looking back now, for me, the hardest part of being a donor was making the decision. I know not everyone has such an easy postoperative course. I felt safe and healthy throughout the process, in the hands of an outstanding transplant team and with the support of family, friends and colleagues. There were no guarantees, but I was reassured by the enormous and excellent track record of the Toronto Living Liver Donor Program, and I am relieved now that all has gone so smoothly, for both of us. I am so happy about my decision. It felt right.

\section{Robert J. Stewart MD}

Department of Surgery, University of Toronto, St. Michael's Hospital, Toronto, Ont.

\section{Marie E. Faughnan MD}

Department of Medicine, University of Toronto, St. Michael's Hospital, Toronto, Ont.

\section{Reference}

1. Brethel-Haurwitz KM, O'Connell K, Cardinale EM, et al. Amygdala-midbrain connectivity indicates a role for the mammalian parental care system in human altruism. Proc Biol Sci 2017;284. pii: 20171731. doi: 10.1098/rspb.2017.1731.

This article has been peer reviewed. 